\title{
Disruptif Teknologi E-Government terhadap Pelayanan Publik Tradisional Masyarakat Surabaya di Era Industri 4.0
}

\author{
Noerma Pudji Istyanto ${ }^{1}$, Muhammad Nasrulloh ${ }^{2}$ \\ ${ }^{1}$ Program Studi Sistem Informasi, Fakultas Teknologi Informasi dan Industri (FTII), \\ Institut Teknologi Telkom Surabaya \\ ${ }^{2}$ Jurusan Sistem Informasi, Fakultas Teknologi Informatika (FTIF), \\ Institut Teknologi Sepuluh Nopember Surabaya \\ Email: ${ }^{1}$ noermapudjiistyanto@ittelkom-sby.ac.id, ${ }^{2}$ nasrullah09@mhs.is.its.ac.id
}

\begin{abstract}
Disruptive technology in the Industrial 4.0 era turned out not only to have an impact on the world of industry and business, but also to the government sector as well as its citizens. At present the Surabaya City Government continues to carry out digital innovations based on egovernment ranging from local financial management systems, e-sdm, e-monitoring, eeducation, e-offices, media centers to integrated public service systems such as e-lampid, ehealth and SSW. However, the development of digital innovation needs to pay attention not only in terms of its benefits, but also needs to be assessed and anticipated the negative impacts arising from disuptive innovations. This study aims to determine the condition and disuptive level of $e$ government technology for the traditional public services of the people of Surabaya in the midst of the development of digital industry 4.0. Researchers used research methods through descriptive, causative, and quantitative approaches by distributing questionnaires to 100 respondents using non-probability sampling techniques by selecting e-Lampid, e-Health and SSW objects as one of the e-government in Surabaya. The benefits of this research will be able to be a reference and recommendation for the Surabaya City Government to continue to pay attention to residents and government officials so that they are not negatively affected by the disruptive technology.
\end{abstract}

Keywords: Disruptive Technology, E-Government, Public Services, Industry 4.0

\begin{abstract}
Abstrak. Distruptif teknologi yang ada di era Industri 4.0 ternyata tidak hanya berdampak pada dunia indstri dan usaha, tetapi juga bagi sektor pemerintahan maupun maupun warganya. Saat ini Pemerintah Kota Surabaya terus melakukan inovasi digital berbasis e-government mulai dari sistem pengelolaan keuangan daerah, e-sdm, e-monitoring, e-education, e-office, media center hingga sistem pelayanan publik terpadu seperti e-lampid, e-health dan SSW. Namun, perkembangan inovasi digital tersebut perlu memperhatikan tidak hanya dari aspek manfaat nya saja, melainkan perlu dikaji dan diantisipasi dampak negative yang timbul dari adanya disuptif inovasi tersebut. Penelitian ini bertujuan untuk mengetahui kondisi dan tingkat disuptif teknologi e-government terhadap pelayanan publik tradisional masyarakat Surabaya di tengah maraknya perkembangan industi digital 4.0. Peneliti menggunakan metode penelitian melalui pendekatan deskriptif, kausatif, dan kuantitatif dengan menyebarkan kuesioner kepada 100 responden menggunakan teknik non probability sampling dengan memilih objek e-Lampid, e-Health dan SSW sebagai salah satu e-government yang ada di Surabaya. Manfaat dari penelitian ini nantinya mampu menjadi reffrensi dan rekomendasi bagi Pemerintah Kota Surabaya agar tetap memperhatikan warga maupun pegawai pemerintahannya supaya tidak terkena dampak negatif dari adanya disruptif teknologi tersebut.
\end{abstract}

Kata Kunci: Disruptif Teknologi, E-Government, Pelayanan Publik, Industri 4.0

\section{Pendahuluan}

Pemerintah Indonesia melalui Kementrian Perindustrian telah menyiapkan strategi "Making Indonesia 4.0" sebagai peta jalan (roadmap) dalam menghadapi persaingan global di Era Industri 4.0. Peta jalan ini melibatkan kolaborasi berbagai pemangku kepentingan (stakeholders) mulai dari institusi pemerintah, asosiasi industri, pelaku usaha, penyedia teknologi, maupun lembaga riset dan pendidikan. Peta jalan Making Indonesia 4.0 memberikan arahaan strategis yang jelas bagi pergerakan industri Indonesia di masa yang akan datang, termasuk di lima sektor (food and beverage, textile and 
apparel, automotive, electronics dan chemicals) yang menjadi fokus dan 10 prioritas nasional dalam upaya memperkuat struktur perindustrian Indonesia.(Pers, 2019a) Di sisi lain, melalui Kementerian Perencanaan Pembangunan Nasional (PPN) atau yang sering dikenal sebagai Badan Perencanan Pembagunan Nasional (Bappenas) juga telah menyiapkan kebijakan-kebijakan pemerintah khususnya 3 (tiga) hal yang perlu dilakukan terkait pengelolaan suatu organisasi. Pertama, suatu organisasi harus dapat membentuk dan memperkuat jaringan kerjasama yang baik dengan sumber daya manusia nya di lingkungan kerja, sehingga mereka dapat terus bertahan dan berinovatif. Kedua, perlunya penguasaan teknologi digital serta kemampuan untuk dapat menganalisis suatu data, dalam hal ini adalah big data. Ketiga, perlunya investasi dalam pembangunan sumber daya manusia (SDM) untuk membentuk SDM yang inovatif dan adaptif pada pasar tenaga kerja. (Pers, 2019b)

Pekembangan Industri 4.0 ini ternyata tidak hanya berdampak sektor industi, tetapi juga berdampak pada sektor pelayanan publik. Pengembangan pelayanan publik berbasis teknologi yang dilakukan oleh pemerintah Indonesia dalam hal ini termasuk pemerintah kota Surabaya saat ini cenderung mengikuti trend global yang mengarah kepada "eGovernment System berbasis Industri 4.0". Model pengembangan ini mampu menyediakan layanan publik yang dapat di akses melalui perangkat elektronik yang terhubung ke jaringan internet tanpa harus datang langsung ke kantor melakukan kontak fisik secara langsung (face-to-face). Adapun upaya pengembangan pelayanan publik berbasis e-government yang telah dilakukan oleh Pemerintah Kota Surabaya saat ini beberapa diantaranya dengan penerapan sistem e-lampid, e-health dan ssw (yang oleh peneliti dijadikan studi kasus dalam penelitian ini) diharapakan dapat membantu mempermudah warga dalam menggunakan layanan publik seperti mengurus administrasi kependudukan, antrian layanan kesehatan di puskesmas atau rumah sakit serta mengurus perizinan secara online. (Istyanto, 2016)

Namun, beberapa fakta dilapangan menunjukkan bahwa sebagian masyarakat Indonesia masih senang dan terbiasa untuk datang ke kantor, kemudian menemui petugas untuk mendapatkan pelayanan. Salah satunya berdasarkan hasil penelitian yang dilakukan oleh Hasniati, ditemukan bahwa dari 450 orang warga Makassar yang dijadikan sampel penelitian terkait penggunaan layanan publik berbasis e-government, $13,6 \%$ pernah menggunakan dan $86,4 \%$ belum pernah menggunkan layanan publik berbasis elektronik tersebut. Menariknya, 48,4\% masih lebih suka dilayanani oleh petugas secara langsung. 38,2 \% merasa lebih nyaman dengan pelayanan berbasis elektronik. Sedangkan 13,4\% sisaya tidak memberikan pendapat (Hasniati; and Syahruddin, 2010). Padahal, keberhasilan pengembangan suatu e-government tidak hanya diikur dari seberapa canggih atau kompleks teknologi yang dibangun, melainkan bagaimana teknologi itu mampu diterima (accept) kemudian di adopsi oleh masyarakat. Oleh karena itu, Pemerintah Kota Surabaya perlu memperhatikan kembali terkait dampak distrupsi teknologi e-government terhadap pelayanan publik tradisional bagi warganya maupun pegawai pemerintah kota yang sebelumnya menjadi tenaga pelayanan publik, jangan sampai ada warga yang tidak bisa mendapatkan pelayanan publik karena ketidakmampuannya dalam mengadopsi teknologi tersebut, bahkan ada pegawai pemerintah yang kehilangan pekerjaannya karena tergantikan oleh teknologi atau mesin.

Untuk itu, tujuan peneliti melakukan penelitian ini yaitu: 1) mengetahui kondisi dan tingkat penggunaan pelayanan publik tradisional yang ada di waga Surabaya; 2) mengeathui karakteristik dan sifat interaksi masyarakat Surabaya yang masih menggunakan pelayanan publik tradisonal; 3) mengetahui faktor-faktor yang mempengaruhi motivasi masyarakat Surabaya yang masih menggunakan pelayanan publik tradisional. 


\section{Tinjauan Pustaka}

\subsection{Disruptif Teknologi}

Disruptif teknologi adalah inovasi yang berhasil mentransformasi suatu sistem atau pasar yang eksisting, dengan memperkenalkan kepraktisan, kemudahan akses, kenyamanan, dan biaya yang ekonomis. Istilah ini dilontarkan pertama kalinya oleh Clayton M. Christensen dan Joseph Bower di tahun 1995. "Disruptive Technologies: Catching the Wave", Harvard Business Review (1995). Disruptif teknlogi menggantikan 'pasar lama', industri, dan teknologi, dan menghasilkan suatu kebaruan yang lebih efisien dan menyeluruh yang bersifat destruktif dan creative. Ciri-ciri dalam era disruption, perubahan menjadi amat cair dan bergerak mengikuti 3S. (Bower, M and Christensen, 1995)

\subsection{Adopsi Teknologi}

Adopsi teknologi adalah proses melalui mana organisasi atau individu memutuskan untuk membuat penuh penggunaan suatu inovasi dalam bisnis sehari-hari mereka (Rogers, 1983). Rogers (1983: 21) mendefinisikan adopsi sebagai "keputusan untuk memanfaatkan sepenuhnya inovasi sebagai tindakan yang terbaik, dan sebaliknya, penolakan adalah keputusan untuk tidak mengadopsi suatu inovasi yang tersedia". Selanjutnya, Rogers menyatakan bahwa pengguna teknologi melalui lima tahap sebelum mereka dapat mengadopsi teknologi baru. Lima tahap yaitu: (1) awarness (kesadaran), (2) interest (ketertarikan) (3) evaluation (evaluasi), (4) trial (percobaan), dan (5) adoption (adopsi). Rogers membedakan proses adopsi dari proses difusi inovasi dalam proses difusi terjadi dalam masyarakat, sebagai proses kelompok; sedangkan, proses adopsi berkaitan dengan individu.

Kerangka adopsi teknologi adalah teori sistem informasi yang telah digunakan dalam studi difusi inovasi dan adopsi, dan untuk menyediakan dasar teoritis untuk memeriksa faktor-faktor yang mempengaruhi adopsi teknologi dalam organisasi (Davis et al, 1989). Menurut teori ini, adopsi dan penggunaan inovasi TI ditentukan oleh pengguna "s keyakinan dan sikap terhadap TI baru (Davis, 1985). Sebagaimana ditunjukkan sebelumnya, model yang paling popular termasuk Teori beralasan Aksi (TRA); Teori Planned Behaviour (TPB); Technology Acceptance Model (TAM); Difusi Inovasi Teori (Rogers, 1983) serta berbagai model lainnya. Sub-bagian berikutnya membahas kerangka kerja ini, karakteristik dan kelemahan mereka.

\subsection{E-Government}

E-government atau pemerintahan elektronik (singkatan dari electronic government, atau yang juga dikenal dengan istilah e-gov, digital government, online government atau dalam konteks tertentu transformational government) merupakan penggunaan teknologi informasi oleh pemerintah untuk memberikan informasi dan pelayanan bagi warganya, urusan bisnis, serta hal-hal lain yang berkenaan dengan pemerintahan. Selain definisi diatas, e-government memiliki banyak pengertian lainnya berdasarkan berbagai sudut pandang mulai dari Negara atau pemerintahan, lembaga internasional hingga para ahli. (Indrajit, 2002)

\subsection{Pelayanan Publik}

Pelayanan publik dalam Keputusan Menteri PAN No. 25 tentang Pelayanan Publik Tahun 2004 berarti, "segala kegiatan pelayanan yang dilaksanakan oleh penyelenggaraan pelayanan publik sebagai upaya pemenuhan kebutuhan penerima pelayanan maupun dalam rangka pelaksanaan ketentuan peraturan perundang-undangan”. Menurut Pasolong (2010:128) Pelayanan pada dasarnya dapat didefinisikan sebagai aktivitas seseorang, kelompok dan/atau organisasi baik langsung maupun tidak langsung untuk memenuhi kebutuhan. Menurut Monir (2003:6) dalam Pasolong (2010:128) mengatakan bahwa pelayanan adalah proses pemenuhan kebutuhan melalui aktivitas orang lain secara langsung. Sedangkan menurut Sinambela (2005:5) dalam Pasolong (2010:128) Pelayanan publik adalah sebagai setiap kegiatan yang dilakukan oleh pemerintah terhadap sejumlah manusia yang memiliki setiap kegiatan yang menguntungkan dalam hasilnya tidak terikat pada suatu produk secara fisik. 


\section{Kerangka d Konseptual}

Model konseptual dari penelitian ini adalah dibangun dari dua kerangka kerja konseptual yang kemudian dikompilasi menjadi model penelitian terkait faktor-faktor adospsi dan disruptif teknologi $e$ government terhadap pilihan saluran pelayanan publik tradisional masyarakat Surabaya.

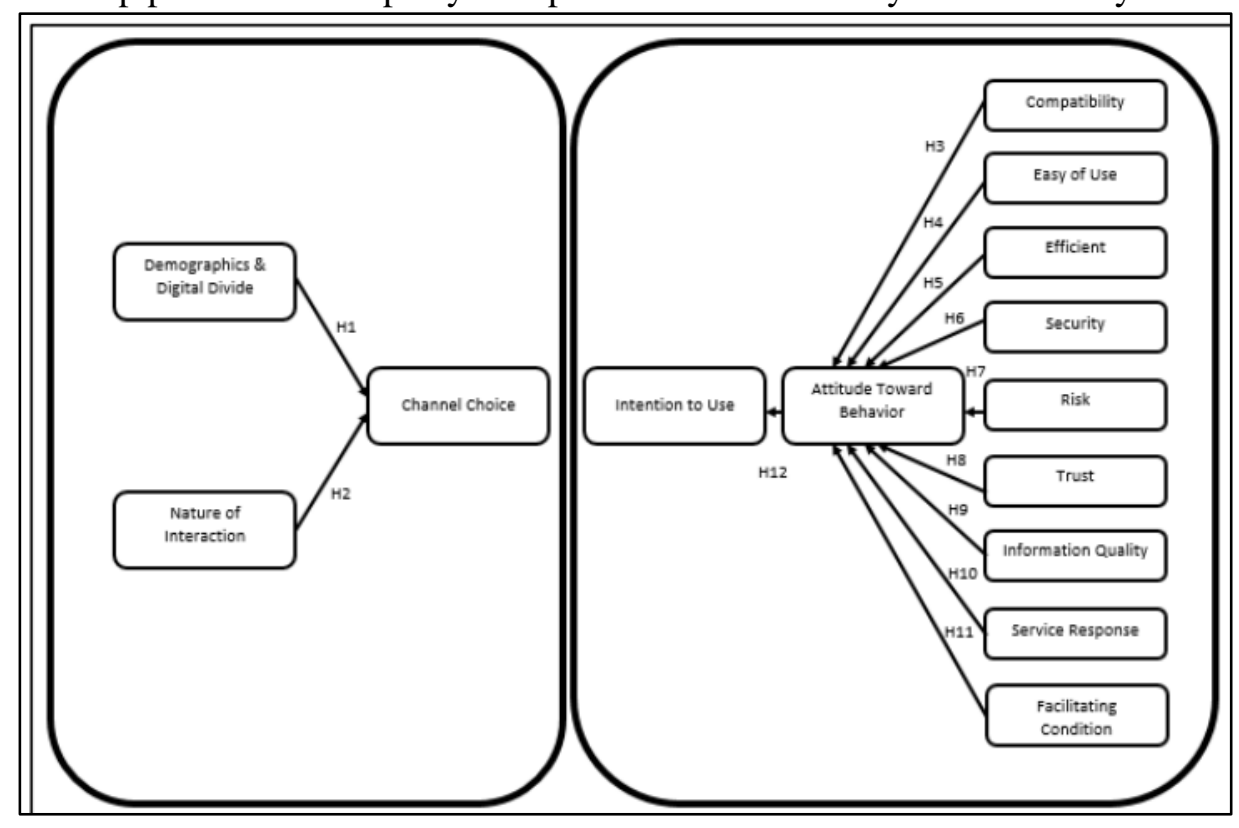

Gambar 1. Kerangka Konseptual Model Penelitian

Kerangka kerja konseptual di sebelah kiri adalah untuk menjawab sistem pengiriman lebih banyak warga Surabaya yang dipilih, antara saluran tradisional atau sistem e-government. dan juga, untuk mengetahui karakteristik dan sifat interaksi warga sebagai pengguna kedua saluran layanan publik. Sementara itu, kerangka kerja konseptual tentang hak adalah untuk mengidentifikasi faktorfaktor yang mempengaruhi warga negara untuk memilih saluran layanan publik mereka. ada 12 hipotesis dalam penelitian ini yang akan dibahas bersama dengan hasil uji hipotesis pada bagian selanjutnya

\section{Metode Penelitian}

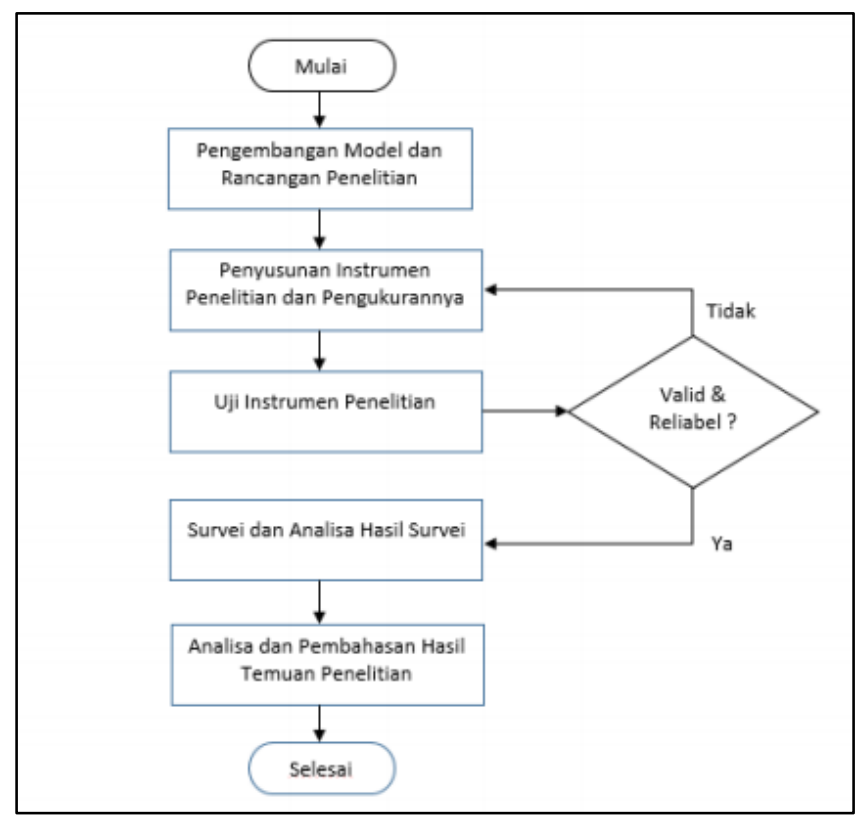

Gambar 2. Tahapan Penelitian 


\subsection{Pengembangan Model dan Rancangan Penelitian}

Konseptual model yang dikembangkan dalam penelitian ini digambarkan konstruknya dan telah lebih detil beserta usulan hipotesisnya pada bagian 4 tentang Kerangka dan Analisa Konseptual. Dalam rangka menguji dan menganalisis model sesuai dengan tujuan yang ditetapkan, maka penelitian yang dirancang kali ini berupa penelitian deskriptif, kausatif dan kuantitatif. Penelitian ini berupa penelitian deskriptif karena bertujuan untuk mengetahui kondisi, tingkat penggunaan, karakteristik dan sifat interaksi masyarakat Surabaya yang masih menggunakan pelayanan publik tradisonal. Sedangkan penelitian ini bersifat kausatif karena bertujuan untuk mengetahui faktor-faktor yang mempengaruhi motivasi masyarakat Surabaya yang masih menggunakan pelayanan publik tradisional.

\subsection{Penyusunan Instrumen Penelitian dan Pengukurannya}

Instrumen penelitian yang digunakan dalam penelitian ini yaitu berupa daftar pernyataan yang dirancang sesuai dengan indikator dan sub-indikator dari variabel-variabel yang ada dalam model konseptual. Pada Tabel 1 oleh peneliti dituangkan menjadi perumusan pernyataan pada kuesioner yang digunakan dalam penelitian untuk membantu menjawab rumusan masalah dari penelitian ini

Tabel 1. Instrument Penelitian sebagai Rumusan Pertanyaan pada Kuisoner

\begin{tabular}{|c|c|c|c|c|c|}
\hline No & Variabel & & Indikator & $\begin{array}{c}\text { Jumlah Item } \\
\text { Pertanyaan }\end{array}$ & $\begin{array}{c}\text { Skala } \\
\text { Pengukuran }\end{array}$ \\
\hline \multirow[t]{5}{*}{1} & \multirow{5}{*}{$\begin{array}{l}\text { Demografi dan } \\
\text { Kesenjangan } \\
\text { Digital }\left(\mathrm{P}_{1}\right)\end{array}$} & $\mathbf{P}_{1.1}$ & Jenis Kelamin & 1 & Nominal \\
\hline & & $P_{1.2}$ & Usia & 1 & Ordinal \\
\hline & & $P_{1.3}$ & Pendidikan & 1 & Ordinal \\
\hline & & $\mathbf{P}_{1.4}$ & Pekerjaan & 1 & Nominal \\
\hline & & $\mathrm{P}_{1.5}$ & Pendapatan & 1 & Ordinan \\
\hline \multirow[t]{3}{*}{2} & \multirow{3}{*}{$\begin{array}{l}\text { Sifat Interaksi } \\
\left(\mathrm{P}_{2}\right)\end{array}$} & $\mathrm{P}_{2.1}$ & Informasi & 2 & Nominal \\
\hline & & $\mathrm{P}_{2.2}$ & Interaksi & 2 & Nominal \\
\hline & & $\mathrm{P}_{2.3}$ & Transaksi & 2 & Nominal \\
\hline \multirow[t]{2}{*}{3} & \multirow{2}{*}{$\begin{array}{l}\text { Pilihan Saluran } \\
\left(Q_{1}\right)\end{array}$} & $Q_{1.1}$ & Saluran Tradisional & 3 & Nominal \\
\hline & & $\mathrm{Q}_{1.2}$ & Saluran E-Government & 3 & Nominal \\
\hline
\end{tabular}

\begin{tabular}{|c|c|c|c|c|c|}
\hline No & Variabel & & Indikator & $\begin{array}{l}\text { Jumlah Item } \\
\text { Pertanyaan }\end{array}$ & $\begin{array}{c}\text { Skala } \\
\text { Pengukuran }\end{array}$ \\
\hline \multirow[t]{9}{*}{$x$} & Persepsi & $\mathrm{X}_{1}$ & Kesesuaian & 4 & \multirow{9}{*}{ Interval } \\
\hline & \multirow{8}{*}{ Pengguna $(\mathrm{X})$} & $\mathrm{X}_{2}$ & \begin{tabular}{|l|} 
Kemudahan \\
\end{tabular} & 4 & \\
\hline & & $\mathrm{X}_{3}$ & \begin{tabular}{|l|} 
Efisiensi \\
\end{tabular} & 3 & \\
\hline & & $\mathrm{X}_{4}$ & Keamanan & 4 & \\
\hline & & $\mathrm{X}_{5}$ & Resiko & 4 & \\
\hline & & $\mathrm{X}_{6}$ & Kepercayaan & 3 & \\
\hline & & $\mathrm{X}_{7}$ & Kualitas Informasi & 4 & \\
\hline & & $\mathrm{X}_{8}$ & Tanggapan Layanan & 4 & \\
\hline & & $\mathrm{X}_{9}$ & Kondisi Memfasilitasi & 4 & \\
\hline \multirow[t]{5}{*}{2} & \multirow{5}{*}{\begin{tabular}{|l} 
Sikap Terhadap \\
Perilaku $(\mathrm{Y})$
\end{tabular}} & $\mathrm{Y}_{1}$ & Baik & 1 & \multirow{5}{*}{ Interval } \\
\hline & & $\mathrm{Y}_{2}$ & Suka & 1 & \\
\hline & & $\mathrm{Y}_{3}$ & Senang & 1 & \\
\hline & & $\mathrm{Y}_{4}$ & Berkesan & 1 & \\
\hline & & $\mathrm{Y}_{\mathrm{s}}$ & Untung & 1 & \\
\hline \multirow[t]{3}{*}{3} & Niat untuk & $\mathrm{Z}_{1}$ & Niat & 2 & \multirow{3}{*}{ Interval } \\
\hline & Menggunakan & $\mathrm{Z}_{2}$ & Rencana & 2 & \\
\hline & (Z) & $\mathrm{Z}_{3}$ & Akan & 2 & \\
\hline
\end{tabular}

\subsection{Uji Instrument Penelitian}

Pada tahapan awal pengujian instrumen penelitian ini dalakukan uji validitas dan reliabilitas terhadap instrument penelitian kausatif kuantitatif guna memastikan ketepatan, kecermatan, kepercayaan dan kehandalan item pertanyaan pada kuisoner yang telah dibuat sebelum disebar pada seluruh responden. Pengujian awal instrumen penelitian dilakukan pada 30 responden sebelum disebar kepada 100 responden untuk menguji validitas dan reliabilitasnya dengan menggunakan alat bantu perangkat lunak SPSS for Windows versi 17.

Tabel 2. Hasil Uji Validasi

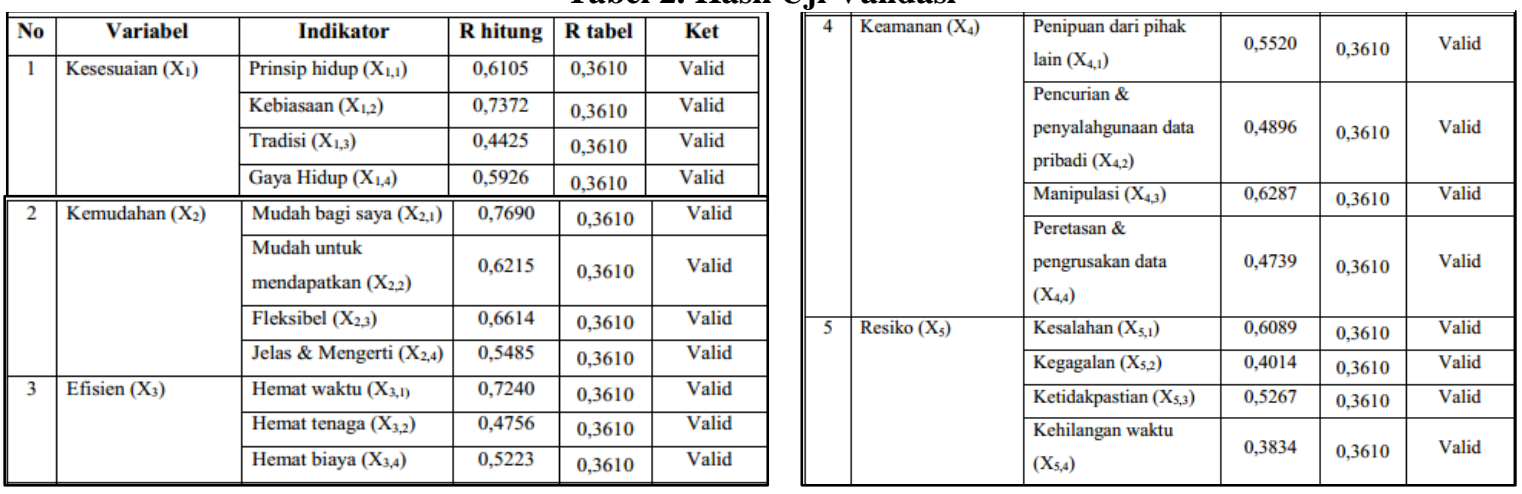




\begin{tabular}{|c|c|c|c|c|c|}
\hline \multirow[t]{3}{*}{ "6 } & \multirow[t]{3}{*}{ 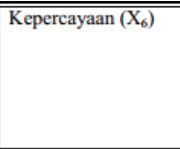 } & "Dapat dipercaya $\left(\mathrm{X}_{6,1}\right)$ & $\begin{array}{ll}0,6691 \\
\end{array}$ & 0,3610 & Valid \\
\hline & & $\begin{array}{l}\text { Dapat diandalkan } \\
\left(\mathrm{X}_{6,2}\right)\end{array}$ & 0,5938 & 0,3610 & Valid \\
\hline & & Terjamin $\left(\mathrm{X}_{6,3}\right)$ & 0,7854 & 0,3610 & Valid \\
\hline \multirow[t]{4}{*}{7} & \multirow[t]{4}{*}{\begin{tabular}{|l} 
Kualitas \\
$\left(\mathrm{X}_{7}\right)$
\end{tabular}} & $\begin{array}{l}\text { Diperbaharui / } \\
\text { Uptodate }\left(\mathrm{X}_{7,1}\right)\end{array}$ & 0,5499 & 0,3610 & Valid \\
\hline & & Akurat $\left(\mathrm{X}_{7,2}\right)$ & 0,4608 & 0,3610 & $\begin{array}{l}\text { Valid } \\
\end{array}$ \\
\hline & & Relevan $\left(\mathrm{X}_{7,3}\right)$ & 0,5947 & 0,3610 & Valid \\
\hline & & Berurutan $\left(\mathrm{X}_{7,4}\right)$ & 0,7182 & 0,3610 & Valid \\
\hline \multirow[t]{4}{*}{8} & \multirow[t]{2}{*}{\begin{tabular}{|l|} 
Tanggapan \\
Layanan $\left(\mathrm{X}_{8}\right)$
\end{tabular}} & $\begin{array}{l}\text { Tersedia selama hari \& } \\
\text { jam kerja }\left(\mathrm{X}_{\mathrm{B}, 1}\right)\end{array}$ & 0,5217 & 0,3610 & Valid \\
\hline & & Dilayani cepat $\left(\mathrm{X}_{8,2}\right)$ & 0,4234 & 0.3610 & Valid \\
\hline & & $\begin{array}{l}\text { Dilayani dengan } \\
\text { ramah }\left(\mathrm{X}_{8,3}\right)\end{array}$ & 0,5210 & 0,3610 & Valid \\
\hline & & $\begin{array}{l}\text { Pelayanan yang sesuai } \\
\left(\mathrm{X}_{\mathrm{g}, 4}\right)\end{array}$ & 0,3941 & 0,3610 & Valid \\
\hline
\end{tabular}

\begin{tabular}{|c|c|c|c|c|c|}
\hline \multirow[t]{4}{*}{9} & \multirow{4}{*}{\begin{tabular}{|l|} 
Kondisi \\
Memfasilitasi $\left(\mathrm{X}_{9}\right)$
\end{tabular}} & Pengetahuan $\left(\mathrm{X}_{9,1}\right)$ & 0,7076 & 0,3610 & Valid \\
\hline & & Keterampilan $\left(\mathrm{X}_{9,2}\right)$ & 0,6310 & 0,3610 & Valid \\
\hline & & \begin{tabular}{|l|} 
Peralatan $\left(\mathrm{X}_{9,3}\right)$ \\
\end{tabular} & 0,6596 & 0,3610 & Valid \\
\hline & & Akses $\left(\mathrm{X}_{9,4}\right)$ & 0,5302 & 0,3610 & Valid \\
\hline \multirow[t]{5}{*}{10} & \multirow{5}{*}{\begin{tabular}{|l|} 
Sikap terhadap \\
Perilaku $\left(\mathrm{Y}_{1}\right)$
\end{tabular}} & Baik $\left(\mathrm{Y}_{1,1}\right)$ & 0,7284 & 0,3610 & Valid \\
\hline & & Suka $\left(\mathrm{Y}_{1,2}\right)$ & 0,6221 & 0,3610 & Valid \\
\hline & & Senang $\left(\mathrm{Y}_{1,3}\right)$ & 0,5348 & 0,3610 & Valid \\
\hline & & Berkesan $\left(\mathrm{Y}_{1,4}\right)$ & 0,3985 & 0,3610 & Valid \\
\hline & & Beruntung $\left(\mathrm{Y}_{1,5}\right)$ & 0,4783 & 0,3610 & Valid \\
\hline \multirow[t]{6}{*}{11} & \multirow{6}{*}{\begin{tabular}{|l|} 
Niat untuk \\
menggunakan $\left(Z_{1}\right)$
\end{tabular}} & Niat ke kantor $\left(Z_{1,1}\right)$ & 0,5624 & 0,3610 & Valid \\
\hline & & Niat online $\left(\mathrm{Z}_{1,2}\right)$ & 0,4539 & 0,3610 & Valid \\
\hline & & Akan ke kantor $\left(\mathrm{Z}_{1,3}\right)$ & 0,6121 & 0,3610 & Valid \\
\hline & & Akan online $\left(\mathrm{Z}_{1,4}\right)$ & 0,4568 & 0,3610 & Valid \\
\hline & & $\begin{array}{l}\text { Rencana ke kantor } \\
\left(\mathrm{Z}_{1,5)}\right.\end{array}$ & 0,6812 & 0,3610 & Valid \\
\hline & & Rencana online $\left(\mathrm{Z}_{1,6}\right)$ & 0,5853 & 0,3610 & Valid \\
\hline
\end{tabular}

Tabel 3. Hasil Uji Reliabilitas

\begin{tabular}{|c|l|c|c|}
\hline No & \multicolumn{1}{|c|}{ Variabel } & Nilai Cronbach's Alpha & Keterangan \\
\hline 1 & Kesesuian & 0,731 & Reliabel \\
\hline 2 & Kemudahan & 0,849 & Reliabel \\
\hline 3 & Efisien & 0,767 & Reliabel \\
\hline 4 & Keamanan & 0,650 & Reliabel \\
\hline 5 & Resiko & 0,669 & Reliabel \\
\hline 6 & Kepercayaan & 0,801 & Reliabel \\
\hline 7 & Kualitas informasi & 0,847 & Reliabel \\
\hline 8 & Tanggapan layanan & 0,749 & Reliabel \\
\hline 9 & Kondisi memfasilitasi & 0,853 & Reliabel \\
\hline 10 & Sikap terhadap perilaku & 0,764 & Reliabel \\
\hline 11 & Niat untuk menggunakan & 0,828 & \\
\hline
\end{tabular}

Berdasarkan Tabel di atas, uji validitas terhadap semua item indikator menunjukkan nilai Korelasi Pearson (product moment) lebih dari 0,3 dsignifikan pada level $\alpha=1 \%$ atau $\alpha=5 \%$. Demikian pula untuk uji reliabilitas terhadap semua item indikator menunjukkan nilai Cronbach Alpha lebih dari 0,6. Dengan demikian, uji awal terhadap instrumen penelitian ini dapat dinyatakan telah valid dan reliable, sehingga dapat digunakan untuk pengolahan instrument selanjutnya.

\subsection{Survei dan Analisa Hasil Survei}

Sumber data utama dalam penelitian ini berasal dari survei yang berupa kuesioner dan wawancara. Data yang dikumpulkan tersebut disebut sebagai data primer. Data primer didapatkan dengan menyebarkan kuesioner yang berisi instrumen penelitian kepada responden yang telah ditetapkan. Selain data primer, penelitian ini juga menggali data sekunder yang sesuai dengan kebutuhan guna menguatkan atau menyempurnakan data primer yang diperoleh.

\subsection{Analisa dan Pembahasan Hasil Temuan Penelitian}

Setelah dilakukan analisis deskriptif dan analisis inferensial, maka tahapan terakhir dalam penelitian ini yakni menganalisis dan membahas temuan keseluruhan dalam penelitian, terkait dengan kesimpulan hasil pengujian model dan saran untuk peluang penelitian yang akan datang. 


\section{Hasil Penelitian dan Pembahasan}

Hasil penelitian deskriptif untuk mengetahui kondisi, tingkat penggunaan, karakteristik dan sifat interaksi masyarakat Surabaya yang masih menggunakan pelayanan publik tradisonal. Sedangkan, hasil penelitian kausatif untuk mengetahui faktor-faktor yang mempengaruhi motivasi masyarakat Surabaya yang masih menggunakan pelayanan publik tradisional.

\subsection{Kondisi dan Tingkat Penggunaan Pelayanan Publik Tradisional yang Ada di Masyarakat Surabaya}

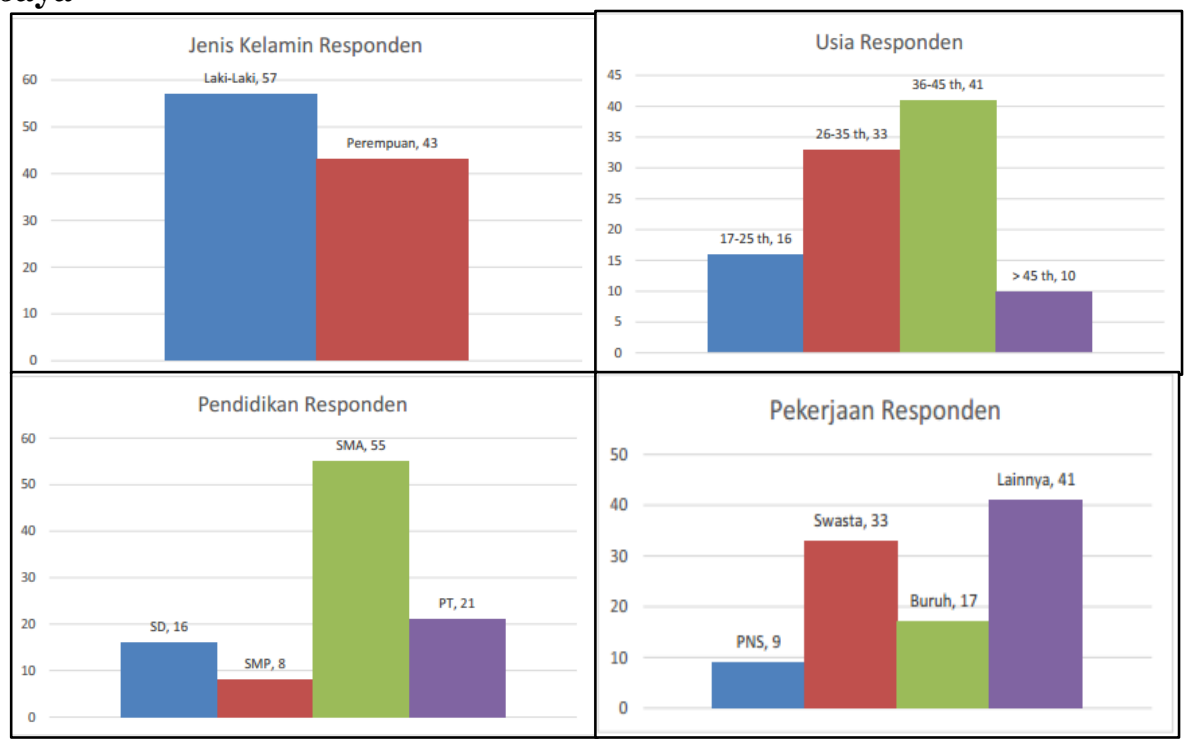

Gambar 3. Kondisi dan Profil Pengguna Pelayanan Publik

Berdasarkan Gambar 3 kondisi dan profil masyarakat Surabaya sebagai responde pengguna pelayanan publik sebagai berikut, dari 100 responden berdasarkan jenis kelamin terdiri dari 57 orang laki-laki, 43 orang perempuan. Berdasarkan rentang usia terdiri dari 16 orang remaja (17-25 tahun), 33 orang dewasa (26-35 tahun), 41 orang paruh baya (36-45 tahun) dan 10 orang lansia (> 45 tahun). Berdasarkan jenjang pendidikan terakhir terdiri dari 16 orang lulusan SD, 8 orang lulusan SMP, 55 orang lulusan SMA dan 21 orang lulusan Perguruan Tinggi. Sedangkan, berdasarkan pekerjaan responden terdiri dari 9 orang Pegawai Negeri Sipil (PNS), 33 orang bekerja di kantor atau perusahaan swasta, 17 orang sebagai buruh serta 41 orang bekerja lainnya.

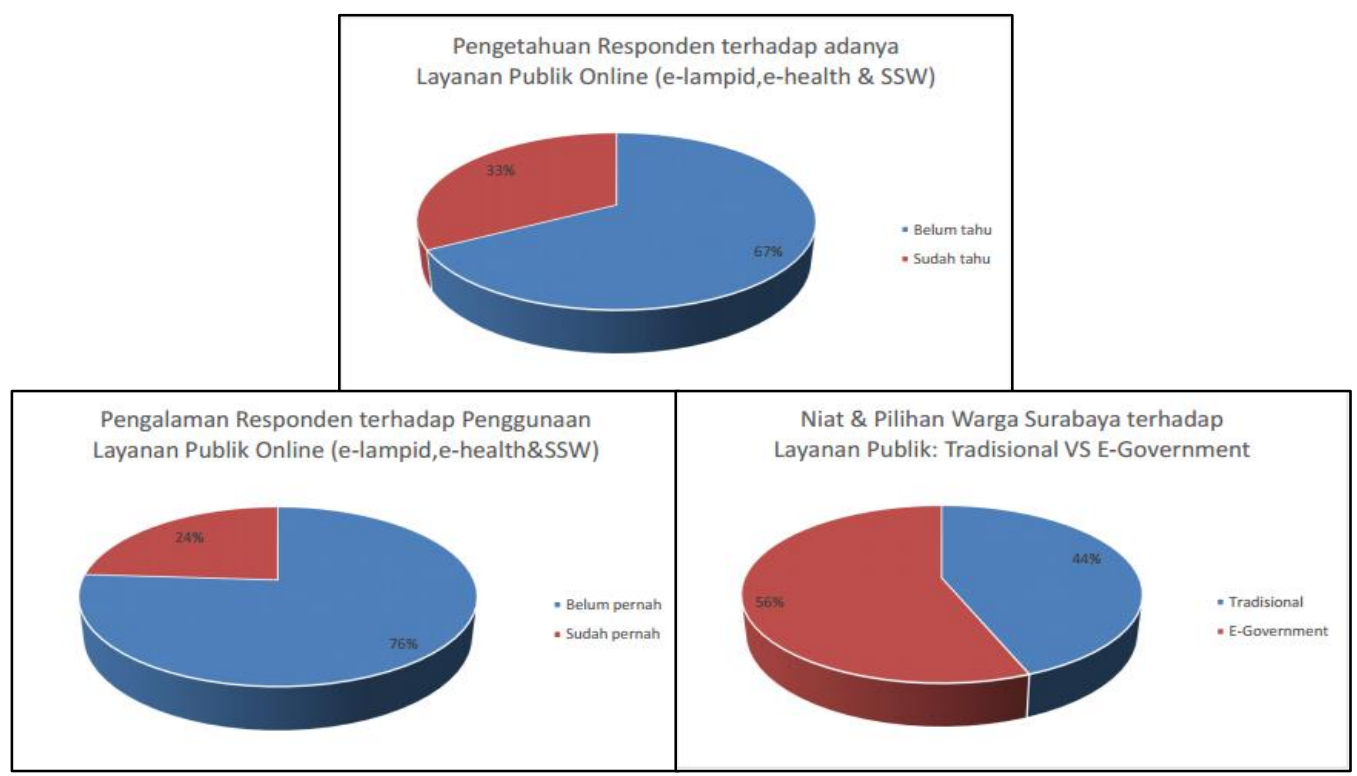

Gambar 4. Tingkat Pengetahuan, Pengalaman dan Penggunaan Pelayanan Publik Tradisional 
Berdasarkan Gambar 4 di atas jumlah responden berdasarkan pengetahuan terhadap adanya layanan publik online di Pemerintah Kota Subaya pada penelitian ini didapatkan sebanyak 67 orang yang belum tahu, sedangkan 33 orang sisanya sudah mengetahui akan adanya layanan publik berbasis online tersebut. Sebanyak 76 orang yang belum pernah menggunakan, sedangkan 24 orang sisanya sudah pernah menggunakan layanan publik berbasis online tersebut. Sebanyak 56 orang yang berniat untuk menggunakan atau memilih layanan publik berbasis online (e-government), Sedangkan 44 orang masih memilih untuk menggunakan layanan publik berbasis tradisional.

\subsection{Karakteristik dan Sifat Interaksi Masyarakat Surabaya yang Masih Menggunakan Pelayanan Publik Tradisional}

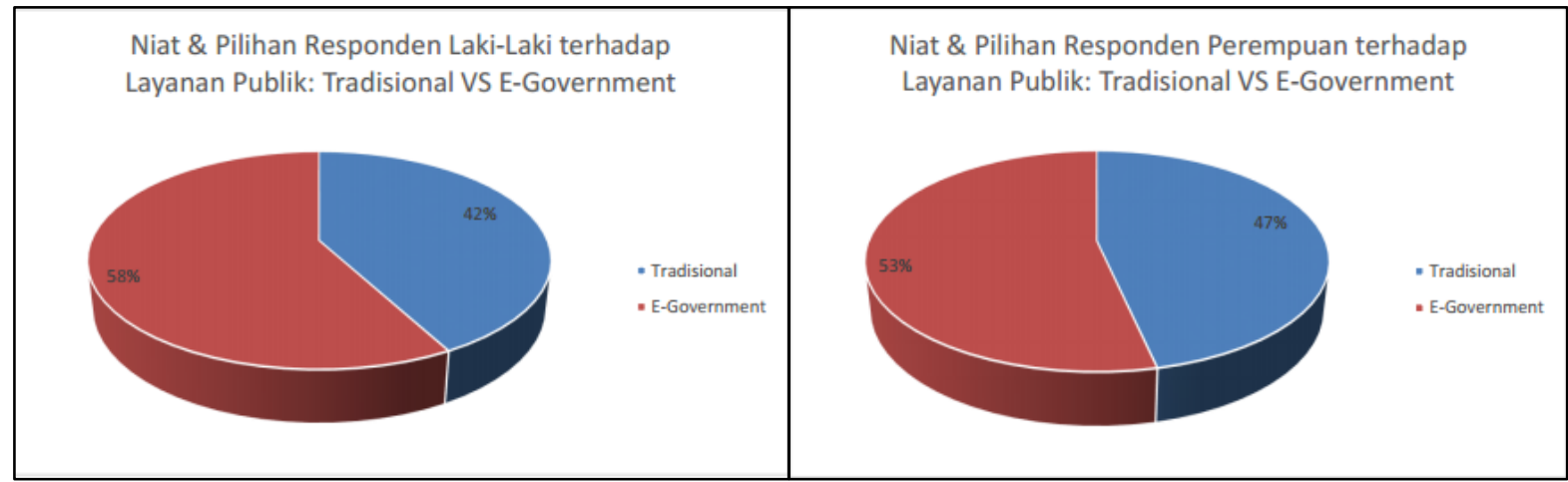

Gambar 5. Karakteristik Pengguna Layanan Publik Berdasarkan Jenis Kelamin

Berdasarkan Gambar 5 di atas karakteristik pengguna layanan publik berdasarkan jenis kelamin sebagai berikut, dari 57 orang laki-laki dan 43 orang perempuan, 24 orang laki-laki (42\%) dan 20 orang perempuan (47\%) masih berniat untuk memilih menggunakan layanan publik tradisional, Sedangkan 33 orang laki-laki (58\%) dan 23 orang perempuan $(53 \%)$ berniat untuk beralih menggunakan layanan publik e-government.

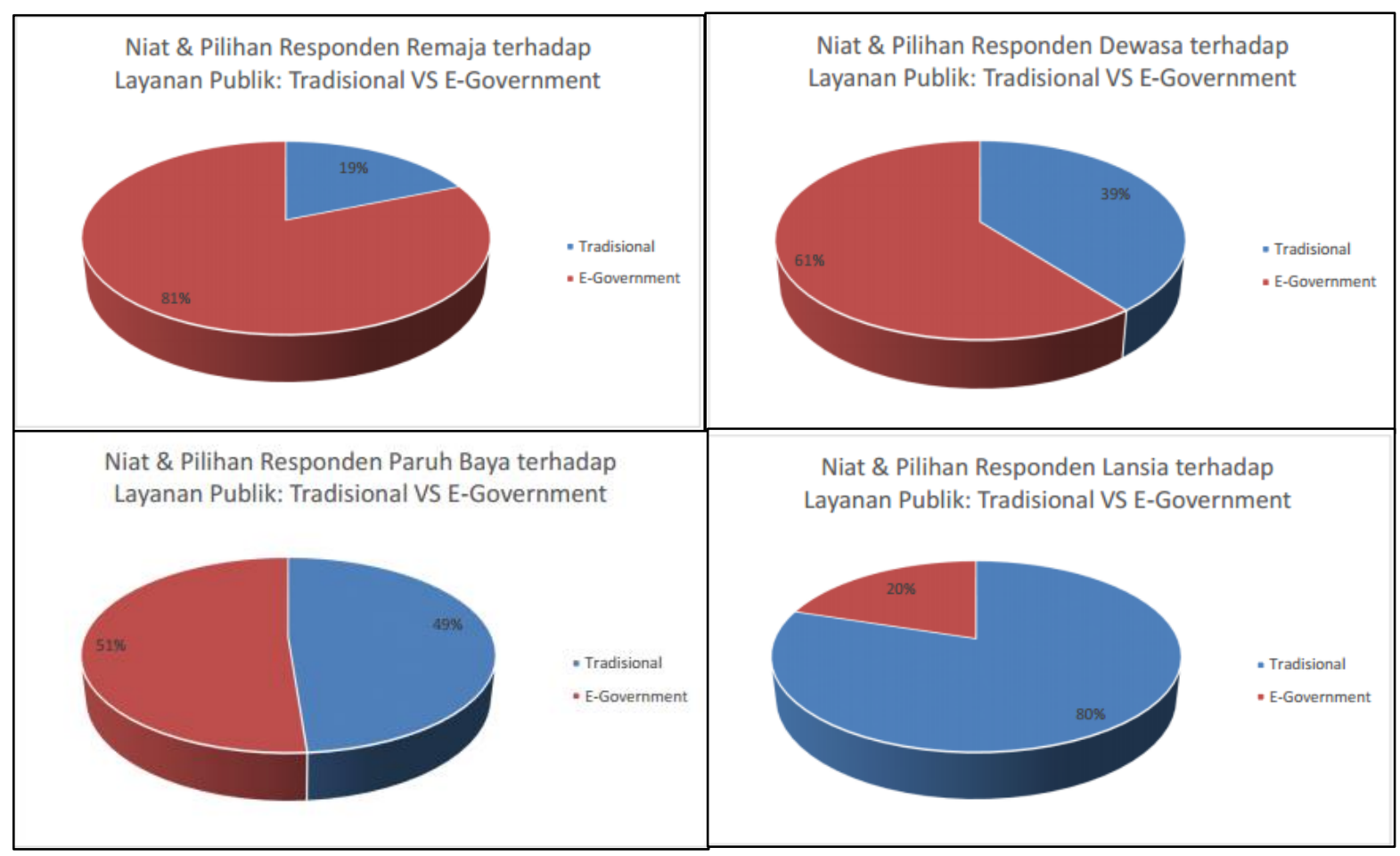

Gambar 6. Karakteristik Pengguna Layanan Publik Berdasarkan Usia 
Berdasarkan Gambar 6 karakteristik pengguna layanan publik berdasarkan usia sebagai berikut, dari 16 orang remaja (17-25 tahun), 33 orang dewasa (26-35 tahun), 41 orang paruh baya (3645 orang) dan 10 orang lansia ( $>45$ tahun). Terdapat 3 orang remaja (19\%), 13 orang dewasa (39\%), 20 orang paruh baya (49\%) dan 8 orang lansia (80\%) masih berniat untuk memilih menggunakan layanan publik tradisional. Sedangkan, 13 orang remaja (81\%), 20 orang dewasa (61\%), 21 orang paruh baya (51\%), dan 2 orang lansia (20\%) berniat untuk beralih menggunakan layanan publik $e$ government.

Tabel 4. Karakteristik Pengguna Layanan Publik Berdasarkan Tingkat Pendidikan

\begin{tabular}{|c|c|c|}
\hline Tingkat Pendidikan & Tradisional & E-Government \\
\hline Sekolah Dasar & 14 orang $(87 \%)$ & 2 orang $(13 \%)$ \\
\hline Sekolah Menengah Pertama & 8 orang $(0 \%)$ & 0 orang $(100 \%)$ \\
\hline Sekolah Menengah Atas & 22 orang $(40 \%)$ & 33 orang $(60 \%)$ \\
\hline Perguruan Tinggi & 0 orang $(0 \%)$ & 21 orang $(100 \%)$ \\
\hline Total & 44 orang & 56 orang \\
\hline
\end{tabular}

Berdasarkan Tabel 4 karakteristik pengguna layanan publik berdasarkan tingkat pendidikan sebagai berikut, 14 orang SD (87\%), 8 orang SMP (0\%), 22 orang SMA $(40 \%)$ dan 0 orang PT $(0 \%)$ masih berniat untuk memilih menggunakan layanan publik tradisional. Sedangkan, 2 orang SD (13\%), 0 orang SMP (100\%), 33 orang SMA (60\%) dan 21 orang PT (100\%) berniat untuk beralih menggunakan layanan publik e-government.

Tabel 5. Karakteristik Pengguna Layanan Publik Berdasarkan Jenis Pekerjaan

\begin{tabular}{|c|c|c|}
\hline Jenis Pekerjaan & Tradisional & E-Government \\
\hline Pegawai Negeri Sipil & 1 orang (11\%) & 8 orang (89\%) \\
\hline Swasta & 9 orang $(27 \%)$ & 24 orang (73\%) \\
\hline Buruh & 14 orang $(82 \%)$ & 3 orang $(18 \%)$ \\
\hline Lainnya & 20 orang $(49 \%)$ & 21 orang $(51 \%)$ \\
\hline Total & 44 orang & 56 orang \\
\hline
\end{tabular}

Berdasarkan Tabel 5 karakteristik pengguna layanan publik berdasarkan jenis pendidikan sebagai berikut, 1 orang PNS (11\%), 9 orang Swasta (27\%), 14 orang Buruh (82\%) dan 20 orang lainnya (49\%) masih berniat untuk memilih menggunakan layanan publik tradisional. Sedangkan, 8 orang PNS (13\%), 24 orang Swasta (73\%), 3 orang Buruh (18\%) dan 21 orang lainnya (51\%) berniat untuk beralih menggunakan layanan publik e-government.

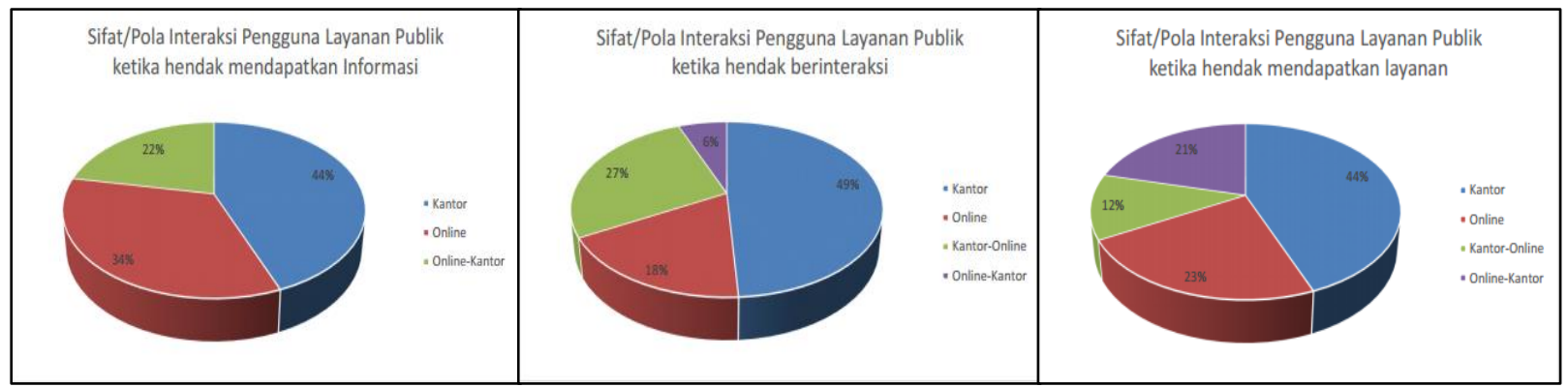

Gambar 7. Sifat Pola Interaski Pengguna Layanan Publik

Berdasarkan Gambar 7 sifat atau pola interaksi pengguna layanan publik sebagai berikut, masyarakat Surabaya tetap memilih datang ke kantor terkait pelayanan publik yaitu, ketika hendak mendapatkan informasi sebesar 44 orang (44\%), hendak berinterkasi sebesar 49 orang (49\%) serta hendak mendapatkan layanan sebesar 44 orang $(44 \%)$. 


\subsection{Faktor-Faktor yang Mempengaruhi Motivasi Masyarakat Surabaya Menggunakan Pelayanan Publik Tradisional}

Berdasarkan hipotesa dan instrument penelitian yang telah ditentukan pada bagian awal penelitian ini sebelumnya, maka didapatkan hasil pengujian sebagai berikut:

Tabel 6. Hasil Uji Hipotesis

\begin{tabular}{|c|l|c|c|}
\hline $\begin{array}{c}\text { Uji } \\
\text { Hipoetasa }\end{array}$ & \multicolumn{1}{|c|}{ Pernyataan } & $\begin{array}{c}\text { Tra } \\
\text { G- } \\
\text { Gov }\end{array}$ \\
\hline H-1 & Demografi dan kesenjangan digital berpengaruh terhadap pilihan saluran & \multicolumn{2}{|c|}{ Ya } \\
\hline H-2 & Sifat interaksi berpengaruh terhadap pilihan saluran & \multicolumn{2}{|c|}{ Tidak } \\
\hline H-3 & Faktor kesesuaian berpengaruh terhadap sikap terhadap perilaku & Ya & Tidak \\
\hline H-4 & Faktor kemudahan berpengaruh terhadap sikap terhadap perilaku & Ya & Tidak \\
\hline H-5 & Faktor efisien berpengaruh terhadap sikap terhadap perilaku & Tidak & Ya \\
\hline H-6 & Faktor keamanan berpengaruh terhadap sikap terhadap perilaku & Tidak & Tidak \\
\hline H-7 & Faktor resiko berpengaruh terhadap sikap terhadap perilaku & Tidak & Tidak \\
\hline H-8 & Faktor kepercayaan berpengaruh terhadap sikap terhadap perilaku & Ya & Ya \\
\hline H-9 & Faktor kualitas informasi berpengaruh terhadap sikap terhadap perilaku & Ya & Tidak \\
\hline H-10 & Faktor tanggapan layanan berpengaruh terhadap sikap terhadap perilaku & Tidak & Ya \\
\hline H-11 & Faktor kondisi memfasilitasi berpengaruh terhadap sikap terhadap perilaku & Tidak & Ya \\
\hline H-12 & Faktor sikap terhadap perilaku berpengaruh terhadap niat untuk menggunakan & Ya & Ya \\
\hline
\end{tabular}

\section{Penutup}

\subsection{Kesimpulan}

Berdasarkan hasil penelitian yang telah dilakukan dapat ditarik kesimpulan dari penelitian ini mengenai Disruptif Teknologi E-government terhadap Pelayanan Publik Tradisional Masyarakat Surabaya di Era Industri 4.0 sebagai berikut:

1. Kondisi dan tingkat penggunaan pelayanan publik tradisional masyarakat Surabaya masih cukup tinggi, hal ini dibuktikan 44\% masyarakat Surabaya masih terbiasa datang ke kantor (face to face) dalam menggunakan pelayanan publik, meskipun sebagian besar masyarakat Surabaya sudah mulai beralih menggunkanan pelayanan publik berbasis e-government.

2. Karakteristik dan sifat interaksi masyarakat Surabaya yang masih menggunakan pelayanan publik tradisional memiliki kecenderungan (trend) dengan latar belakang usia, pendidikan maupun pekerjaan. Masyarakat Surabaya yang usianya semakin lanjut ( $>45$ tahun) dengan tingkat pendidikan terakhir semkin rendah ( lulusan SD dan SMP) serta pekerjaanya sebagai buruh atau lainnya cenderung masih memilik untuk menggunakan layanan publik tradisional

3. Faktor utama yang mempengaruhi motivasi masyarakat Surabaya yang masih menggunakan pelayanan publik tradisional yaitu aspek kesesuaian dengan tradisi yang sudah melekat di masyarakat, kemudian aspek kemudahan sesuai dengan kemampuan penggunaan teknologi yang masih terkendala untuk masyarakat yang sudah lanjut usia dan memiliki latar belakang pendidikan rendah, serta aspek kepercayaan dan kualitas informasi yang didapatkan dianggap lebih baik oleh masyarakat jika datang langsung ke kantor.

\subsection{Saran}

Berdasarkan keseluruhan penelitian didapatkan saran-saran yang dapat diberikan untuk pengembangan penelitian, baik bagi penelitian selanjutnya maupun untuk kepentingan institusi atau pihak-pihak lain. Saran pada penelitian ini adalah sebagai berikut:

1. Penelitian selanjutnya disarankan bekerja sama langsung dengan Pemerintah Kota Surabaya agar menjadi program sensus pelayanan public berbasis e-government sehingga mendapatkan dukungan secara langsung serta penuh guna mengambil sampel yang lebih besar dan signifikan lagi dengan teknik sampling serta instrument penelitian yang lebih spesifik untuk hasil yang lebih represntatif dan akurat terkait potret kondisi actual \& dukungan penggunaan layanan publik berbasis $e$ government di masyarakat Surabaya.

2. Pemerintah Kota Surabaya tetap perlu memperhatikan warganya yang masih memilih menggunakan pelayanan publik berbasis tradisional sehingga dapat memberikan pelayanan yang terbaik buat seluruh warganya. 


\section{Referensi}

Bower, J. L., M, C. and Christensen, M. (1995) Disruptive Technologies: Catching the Wave. America.

Carter, L., \& Belanger, F. (2005). The utilization of e-government services: Citizen trust, innovation and acceptance factors. Information Systems Journal, 15, 5-25.

Davis, F. (1989). Perceived usefulness, perceived ease of use, and user acceptance of information technology. MIS Quarterly, 19(2), 319-339.

Gupta, B., Dasgupta, S., \& Gupta, A. (2008). Adoption of ICT in a government organization. Journal of Strategic Information Systems 17, 140-154.

Hasniati; and Syahruddin, M. H. (2010) Kebijakan Pengembangan Pelayanan Publik Berbasis eGovernment (e-Services) di Makassar, Jurnal Infokom. Makassar.

Indrajit, R. E. (2002). E-Government: Strategi Pembangunan dan Pengembangan Sistem Pelayanan Publik Berbasis Teknologi Digital. Yogyakarta: Andi.

Istyanto, N. P. (2016) 'Evaluation of Public Service Strategy Chosen by Citizens of Surabaya: Traditional Vs E-Government (Case Study: E-Lampid, E-Health \& Ssw)', in The 2nd International Seminar on Science and Technology (ISST) 2016 Volume 2. Surabaya: Department of Civil Engineering Postgraduate Program Institut Teknologi Sepuluh Nopember, p. 523.

Kanat, I. E., \& Ozkan, S. (2009). Exploring citizens' perception of government to citizen services: A model based on theory and planned behavior (TBP). Transforming Gov-ernment: People, Process and Policy, 3(4), 406-419.

Lin, F., Fofanah, S. S., \& Liang, D. (2011). Assessing citizen adoption of eGovernment initiatives in Gambia: A validation of the. Government Information Quarterly 28, 271-279.

Ozkan, S., \& Kanat, I. E. (2011). e-Government adoption model based on theory of planned behavior:. Government Information Quarterly 28, 503-513.

Pers, S. (2019a) Making Indonesia 4.0: Strategi RI Masuki Revolusi Industri Ke-4, Kemenperin.go.id. Available at: https://kemenperin.go.id/artikel/18967/Making-Indonesia-4.0:-Strategi-RIMasuki-Revolusi-Industri-Ke-4 (Accessed: 1 September 2019).

Pers, S. (2019b) Menteri Bambang: Indonesia Siap Hadapi Tantangan Era Digital dan Industri 4.0, bappenas.go.id. Available at: https://www.bappenas.go.id/id/berita-dan-siaran-pers/menteribambang-indonesia-siap-hadapi-tantangan-era-digital-dan-industri-40/ (Accessed: 1 September 2019).

Reddick, C. G., \& Turner, M. (2012). Channel choice and public service delivery in Canada: Comparing e-government to. Government Information Quarterly 29, 1-11.

Rogers, E. M. (1983). Diffusion of Innovations. New York: Free Press.

Torres, L., Pina, V., \& Acerete, B. (2005). E-government developments on delivering public services among EU cities. Government Information Quarterly, 22(2), 217-238.

West, D. M. (2004). E-government and the transformation of service delivery and cit-izen attitudes. Public Administration Review, 64(1), 15-27.

Yong, J. S. (2005). ZE-Government in Asia. Enabling Public Service Innovation in the 21st Century. Singapore: Times Edition-Marshall Candevish. 